\title{
NEUROPSYCHIATRY OF CREATIVITY
}

${ }^{1}$ Marco Mula, ${ }^{2}$ Bruce Hermann, ${ }^{3}$ Michael R Trimble

1)Epilepsy Group, Atkinson Morley Regional Neuroscience Centre, St George's University Hospital, London and Institute of Medical and Biomedical Sciences, St George's University of London, United Kingdom

2)Department of Neurology, University of Wisconsin School of Medicine and Public Health, Madison WI

3)UCL Institute of Neurology, Queen Square, London, United Kingdom

\section{Corresponding author:}

Dr Marco Mula MD PhD

Epilepsy Group

Atkinson Morley Regional Neuroscience Centre

St George's Hospital

Blackshaw Road

London SW17 0QT

UK

Tel: +442087254107

FAX: +442087254591

Email:mmula@sgul.ac.uk 


\begin{abstract}
In this paper we review in brief the development of ideas that over time have tried to understand why some individuals are more creative than others, and what may be the neurobiological links underlying artistic creativity. We note associations to another unique human idea, that of genius. In particular we discuss frontal-temporal dementia and bipolar, cyclothymic mood disorder as clinical conditions that are helping to unravel the underlying neuroanatomy and neurochemistry of human creativity.
\end{abstract}

Key words: creativity, bipolar disorder, dementia, frontal lobe 


\section{Introduction}

Defining creativity is difficult, especially when addressing the subject in relation to the arts. The polymath author philosopher Arthur Koestler in The Act of Creation gave the term 'bioassociation' to distinguish "routine skills of thinking on a 'single plane', as it were, from the creative act, which...always operates on more than one plane". It is embedded within a meta-cognition, which began for our ancestors with the "dawn of symbol-consciousness...a kind of diluted Eureka process, spread out in time..." [1]. The psychoanalyst Anthony Storr approved of the definition as the "the ability to bring something new into existence", emphasising the unconscious as well as the conscious contributions to creativity and the accentuation and synthesis of opposites [2]. Creativity in these terms suggests a phenomenon unique to Homo sapiens whereby something new is created which has some kind of subjective value (e.g., an idea, a joke, a literary work, a painting or musical composition, a solution, or an invention). There is a qualitative impetus behind any given act of creation, and it is generally perceived to be associated with intelligence and cognition. However, a further aspect has to be considered. Other authors have emphasised the social benefits of the created entity. According to Plucker, creativity involves the interactions among aptitude, process and environment by which an individual or group produces a perceptible product that is both novel and useful as defined within a social context [3].

How can this process be translated into cognitive terms using a neurobiological perspective? In this regard, some elements are relevant, namely the role of frontolimbic networks and the specialisation of brain hemispheres; one way of exploration of 
creativity is with the techniques of neuroscience, but another is by study of the influence of brain disorders.

\section{Some history}

The French physician Moreau de Tours, in 1859, referred to creativity as a névrose, a theme taken up by Cesare Lombroso. Lombroso's view was that genius was a variety of insanity. Lombroso documented the relevant signs in people of genius. These ranged from the small stature of Aristotle, Plato, Mozart, Beethoven, Charles Lamb, De Quincey and Blake, to those of greater height than average, such as Goethe, Petrarch, Schiller, Tennyson and Whitman. A cretin-like physiognomy was accredited to Socrates, Rembrandt, Pope and Darwin, while left handedness was a trait of both Leonardo da Vinci and Michelangelo. Lombroso referred to genius as a "true degenerative psychosis belonging to the group of moral insanity". In a potential reference to the later link with bipolar disorders he further commented "...but the most special characteristic of this form of insanity appears to reduce itself to an extreme exaggeration of two alternating phases, erethism and atony, inspiration and exhaustion..." [4].

Several writers at this time noted an association between "excessive activity" of the intellect and "expansive forms of mental aberration". Nisbet brought forward the known neuroanatomical and neurophysiological evidence, placing Lombroso's theories on an apparently better scientific standing. For him “...apparently at the opposite poles of the human intellect, genius and insanity are, in reality, but different phases of a morbid susceptibility of, or want of balance in, the cerebrospinal system" [5].

Nisbet like Lombroso gave countless examples of men of genius who showed one or other of the stigmata of mental illness, or in whom it could be shown in their families. 
Nisbet reflected on the creative process, noting that: "The man of genius overflows with ideas; countless memories are stirred in his brain, and he discovers combinations and affinities in facts, tones and colours that lie beyond the scope of the ordinary mind. In all these accomplishments, the madman is his equal. Both the man of genius and the madman owe their characteristics of thought and action to the excessive stimulation, the depression, or the excitability of certain regions of their brain." [5].

Sully [6] referred to "the wide and penetrating vision of the poet is the correlative of his quick, delicate, and many-sided sensibility." This "exquisite sensibility" was connected to "a delicate poise of nervous structure". In other words, there was something about the organisation of the brain in creative people, which is associated with the development of such talent. This organisation also led to a tendency for suffering, solitude, a mood of discontent, all "unfavourable to mental health". Creation involved "the full tension of the mental powers, the driving of the cerebral machine at full speed".

Sully noted the great strain that such creative tensions involved, and how this "stress and storm should afterwards leave the subject exhausted and prostrate" [6]. The possession of the tendency to genius also carries with it the proclivity for breakdown. The man of talent follows creatively lines already laid down, the man of genius "is a mode of variation of human nature which, though unfavourable to the conservation of the individual, aids in the evolution of the species."

Three different views were therefore crystallising. In one, the genius was seen to be a divine inspiration. In the second it was considered a reflection of mentally abnormality, 
in the other, the presence of genius itself was somehow damaging to the mental health, both of the creator and the recipients of their creativity! Melancholy, excitement, exhaustion became common themes.

The first perspective, that of creativity, especially genius as a reflection of divine intercession has almost lost its relevance in a more secular. The second idea could at least in part be rejected on account of the number of geniuses that have lived without evidence of insanity, and on the grounds of having no real scientific substance other than multiple anecdotes.

Most authors who discuss artistic creativity do not single out poetry as a different form of genius, for example to be distinguished from musical or mathematical genius, but some clearly have. However, the evidence, as it appears in later studies, actually does support a distinction between different forms of creativity and their relationship to psychopathology. Russell Brain put it thus: “The poet, who uses words to evoke images, and images to move and delight, is the very opposite of the thinker, who must detach his thought from the concrete and purge it of feeling. Can anyone doubt that these differences between geniuses and ordinary folk and between one type of genius and another depend on differences of neural organisation..." [7].

\section{Towards a neurology of creativity}

From a cognitive point of view, observational learning, memory, cognitive flexibility and novelty seeking represent basic elements of creativity. Observational learning is defined as the addition of a novel behaviour to an individual's behavioural repertoire via watching another, irrespective of the cognitive processes used in the learning of this behaviour [8]. While this ability may not be strictly required to produce an innovative 
product, along with memory for the learned act it is part of the creative process. Novelty seeking can be defined as an exploratory activity in response to novel stimulation while cognitive flexibility implies a fluidity of thought, a huge move away from the concrete. Thus, central to artistic creativity has been the development of symbolic thought, allowing the mind disengagement from the immediate present and meta-representation given over to intentions, beliefs and recursive "generative processes of combining and recombining items into virtually infinite numbers of novel sequences" [9]. Theory of mind, mental time travel and both linguistic and non-linguistic symbolic representations are a part of human creative ability.

While it is clear that these attributes are not tout á fait the prerogative of the human mind. From an evolutionary perspective it is quite unclear when over the past million years or so they coalescence emerged to provide for us such a rich world of imagination, reflected in the arts. However, their emergence must be related at least to the development of the hominid brain, revealed in part by differences between the brains of Homo sapiens and, for example, our nearest living relatives the chimpanzees. To discuss this further is beyond the scope of this paper, but certain cerebral structures and circuits have become singled out for attention. These include areas of frontal and temporal cortex, the basal ganglia and the cerebellum [10].

The importance of the frontal lobes is central to almost all studies of creative ability and converging evidence from both PET, MRI and EEG studies suggest that the activation of frontal lobes clearly differentiates creative from non-creative tasks [11]. However, as discussed by Flaherty [12], creative drive and the generation of ideas depends on interactions between the frontal lobes with the temporo-limbic structures. Further, these studies also suggest that the frontal lobes of more creative individuals are more efficient. Thus, creative people may be endowed with brains that are capable of storing 
extensive specialized knowledge in their temporo-parietal cortex, be capable of frontal mediated divergent thinking and have a special ability to modulate the frontal-limbic connections.

From a neurobiological point of view, novelty seeking has been classically associated to dopamine levels and the frontal lobes [13]. In this regard, dopamine seems to modulate not only novelty seeking but also reinforcement as demonstrated in both drug-seeking and risk-seeking behaviours.

Evidence suggests that the cerebellum is involved in the link between seeing and doing - or processing movements and behaviour that have been observed, for the individual to produce them later [14]. The cerebellum is also critically involved in the internal representation of action, an ability used to understand and learn the skills of others by observation. In this regard, it is impossible not to mention the role of mirror neurons. Mirror neurons are believed to be involved in understanding the behavioural actions made by others by matching the visual description of an action with the internal motor representation of the same action in the observer [15]. The integration of perceptual predispositions with the motor system involving cortical-basal ganglia thalamic reintegrative loops represents important neuronal elements for creativity [16].

Is there a hemispheric dominance? An analysis of EEG coherence pointed to the important role of the right hemisphere in creative people [17]. Bogen and Bogen [18] viewed creative innovation as a process dominated by the right hemisphere, which is associated with global and holistic processing. Findings have shown positive correlations between figural and verbal creativity and cerebral blood flow in the right precentral gyrus. Indeed, studies have shown a correlation between level of activity and assessments of creativity in the right cerebral hemisphere [19]. Jung-Beeman et al. [20] 
reported that the right anterior superior temporal gyrus was particularly involved with the Aha! moment of insight when problem solving. However, this is not the whole story, since many other studies observe significant correlations in both cerebral hemispheres, depending on the type of activity investigated, and note the importance of the left hemisphere for some language dominated cultural creativity has been acknowledged since the time of Broca.

Finally, it is impossible not to mention the role of the unconscious and sleep. The former has received considerable attention in the past, even if now avoided or elided by modern neuroscience. More recently the importance of sleep in enhancing creative problem solving for items that were primed before sleep has been examined [21]. This seems to be particularly the case for REM sleep and not to be the result of selective improvements in memory [22].

\section{Neurological illness and creativity}

When attempting to understand the neurobiology of creativity and creative processes, one does not immediately look to the neurodegenerative diseases for insight [23]. The obvious and reasonable view of progressive neurodegenerative processes is that they operate only to impair cognition and function in a progressive fashion. However, a particularly interesting set of findings concerns the emergence of artistic talent in a subset of patients with dementia who developed "incipient and impassioned abilities in visual arts". These patients have been most actively studied by Miller and colleagues [24-25]. In addition to the emergence of visual arts. They reported that new onset creativity extended occasionally to obsessions with word punning and poetry [25].

These newly emergent artistic and creative behaviors have been observed primarily in nonAlzheimer's dementia, specifically, those with Primary Progressive Aphasia (PPA), a particular 
form of Frontotemporal Dementia (FTD) [27]. The primary signature of the semantic variant PPA (svPPA) is progressive loss of word meaning with preserved fluency. In addition to the impact on language function, noted in some patients is the emergence of rigidity and behaviors. svPPA tends to be an asymmetrical disease, typically preferentially affecting the left hemisphere, the temporal lobes more than frontal lobes and especially the anterior temporal poles as well as the insula, amygdala, and anterior hippocampus.

The underlying theory regarding these findings assumes that left-hemisphere and frontal activities normally inhibit right-hemisphere and posterior functions, and thus left frontal disease would result in a release of right frontal and posterior functions. Miller and Miller reported that de novo artistic ability was most notable primarily in patients with svPPA with accompanying left frontal disease with intact right posterior anatomy-thereby with the socalled neural capacity to appreciate, integrate, and create compositions, but only when combined with spared dorsolateral and medial frontal cortices [26]. Comparison of atrophy patterns, between subjects displaying artistic ability versus those without showed that the artistic individuals had relative sparing of the dorsolateral and anterior cingulate a cortices within the frontal lobes while sharing a pattern of temporal atrophy with their nonartistic counterparts. This suggested that creative for abilities sparing of particular frontal lobe anatomy was important. In contrast those with the behavioral variant FTD, had greater frontal than temporal involvement, and typically reveal impairments in abstract thinking and decreased creativity [25].

Further, the artworks tended to contain common themes, tending to be "photorealistic" with absence of abstraction and focusing on animals, people, and landscapes. Also striking the authors was a degree of intensity and productivity toward their subject matter.

Some individuals would obsessively rework their compositions over and over again or create dozens of similar creations. While these artistic behaviors mimicked the compulsive qualities noted in temporal lobe atrophy predominant FTD patients who were not artistically inclined such as picking skin, folding napkins, or squashing bugs - the content of their obsessiveness 
was outwardly more productive. Instead of seeing this as a negative or problematic issue, we note that there are many examples where compulsive behavior can be beneficial in the creative process. Further support for this notion has been observed in the savant phenomenon, where seemingly impossible artistic or mental abilities are performed by individuals who have a profound singular interest.

What we are left with is the challenge of better understanding the difference between patients with temporal predominant FTD who are compulsive and display relkease of artistic behavior versus those who are compulsive without overt artistic output.

Interestingly, in light of the Gastant Geschwind syndrome in epilepsy, they also identified a small group of patients with hypergraphia [28]. This is a form of hypergraphia, a compulsive writing behavior - excessive labeling of all objects in the environment, detailed minute by minute accounting of daily events, scribbling over available surfaces - a few of whom also display what appears to be new onset artistic writing (their hypergraphia took on a productive and relatively coherent formulation leading to a small folio of poetry, a collection of letters with visual collaged elements, and a self-help novel). In the future, looking into the imaging and neuropsychological characteristics that separate this hypergraphic cohort from other hypergraphic patients might allow us to capture the elements that allowed for these artistic qualities to present above and beyond the compulsive tendencies to create. For now, our best insights have come from patients with different variants of PPA.

It should be recalled that in classic Alzheimer's disease in contrast to FTD visuoconstructive abilities are lost in the early stages of disease, perhaps attributable to the prominent and early parietal involvement [29].

Thus, particular neurological disorders may result in the emergence of behaviors that one could call articitic and creative dependant on the sight, side and speed of change to the damaged CNS tissue. 


\section{Creativity and bipolarity}

We have noted the role of dopamine and fronto-limbic structures in creativity, and it is impossible not to mention all conditions where such networks are disrupted, especially psychiatric disorders. A comprehensive literature points to a close association between psychopathology and creativity. The works of Andreasen [30], Jamison [31], Post [32], Ludwig [33-34] and Trimble [35] have pointed out a high prevalence of mental illnesses, in particular mood disorders, among famous creative people (e.g. writers, poets, painters, composers and so on). Of singular interest is the lack of great creativity in the arts in people with schizophrenia. The link between creativity and bipolarity has attracted the interest of clinicians and neuroscientists for decades. Studies aimed at dissecting out principal components of mania showed that "feeling creative" is frequently reported by patients with bipolar disorder [36]. They often describe themselves as "very artistic and creative" with "bursts of inspiration or creativity", "mentally very sharp, brilliant and clever" [36]. Interestingly enough, an important element in such a self-perception is represented by the increased "sensitivity to the forms and harmony in nature". This is a common experience in manic states with patients describing colours "more colourful" as well as smells more "intense". Besides, these experiences are accompanied by an increased salience. These aspects are strictly connected with psychomotor activation that represents the cognitive component of the manic experience. In this regard, it is important to distinguish between psychomotor activation and euphoria. Both of them represent the pure components of mania. However, euphoria parallels the grandiosity symptom cluster described by Beigel and Murphy [37] that brings to mind images of happy, laughing, and flirtatious patients with mania. Psychomotor activation represents the cognitive component of mania including most of the DSM-coded typical symptoms of mania: "racing thoughts", "constantly 
active", "shifting interests" and "vigorous and energetic" [36]. Since Robertson's description of hilarious mania [38], euphoria has always been identified with mania [39] but psychomotor activation represents the fuel feeding the energetic spirit fire of mania. Classic psychopathology clearly shows that bipolar patients perceive themselves as extremely creative. However, it is important to understand whether such creativity is only self-perceived or objectively identifiable. Studies looking specifically at creativity in patients with mood disturbances showed that, even using quite a wide definition of creativity, no more than $8 \%$ of patients with bipolar or unipolar disorders could be considered creative [40-41], suggesting that creativity and bipolarity are connected in a complex fashion. A cross-sectional study looked at temperament/personality features in patients with mood disorders in euthymic phase, and creative and healthy controls [42]. Creative controls and euthymic mood disorder patients presented a considerable overlap suggesting that sub-threshold psychiatric symptoms, or temperamental features, rather than full blown psychiatric disorders, play a major role in creativity [40]. Although creative individuals have a significant excess of bipolarity, manicdepressive illness is relatively uncommon [31], further confirming that dilute temperamental forms of bipolarity may sub-serve creativity [40]. Certainly, talent is a necessary ingredient but it is likely that creativity in different professional domains is related to optimal mixes of temperamental and cognitive profiles [40-41]. In this regards musically and poetically creative individuals may differ significantly from gifted architects, mathematicians or politicians, but few studies have examined these issues [35].

\section{Altered states of consciousness}


Finally, another important question is: do altered states of consciousness facilitate creativity? Evidence for this unqualified claim is easy enough to find in the literature. For instance, drugs - alcohol and opium, in particular - have a long standing reputation of fostering creative inspiration [43]. Arnold Ludwig [44] carried out a 10 year study of the link between mental illness and creativity by gathering together biographies of 1,004 "extraordinary men and women". One quarter of the sample was female, eighteen different professions were represented, and all were selected from biographies which were reviewed in the New York Times Book Review from 1960-1990. He analysed the family background, broken homes, family size and birth order, physical health, education and social behaviour, encounters with the law, and several other factors he considered relevant to the nurturing of creativity. He also developed a Creative Achievement Scale to measure relative eminence, the scores on this scale correlating highly with the number of lines allotted to the individual in the Encyclopoedia Brittanica and the Encyclopoedia Americana.

Ludwig's conclusion was that people in the creative arts suffer from more psychopathology than other creative people. He wrote: "However, no single pattern of mental illness characterises all of the creative arts professions. Although alcoholism and depression are widespread within the creative arts, each profession in its own way shows a distinctive pattern of psychopathology. Illicit drug use is more common among musical performers and actors. Musical composers, artists, and nonfiction writers suffer mostly from alcoholism and depression throughout their lives. Musical entertainers, architects and actors are relatively free from depression. Poets show a high prevalence of both mania and psychosis. Poets, actors, fiction writers, and musical entertainers are more likely to 
attempt suicide. Among all those in the creative arts, only architects and designers, and to some extent non-fiction writers, show few signs of mental instability" [44].

A few probing questions quickly expose where, exactly, things go wrong here: How many creative ideas occur in the normal mode of consciousness, whatever that may mean? What is the incidence and prevalence, compared to the general population, of creative achievement for people suffering from a mental illness and how is that fostered by non-prescription drugs and dampened by psychotropic agents used in management? Certainly without consciousness creativity cannot develop, but the statement that altered states of consciousness facilitate creativity - unqualified like this, is unproven. Associations between different states of consciousness, twilight states, sleeping and dreaming, trances, and drug-induced transcendental experiences and creativity have been poorly explored, even if written about often and in anecdotal form, they were a predominant theme of which Romantic literature, and in some ways echo back to the Greek ideas of the furor poeticus.

\section{Conclusions}

Creativity is a complex phenomenon with a number of neurobiological variables, sociological, cultural, evolutionary and neurobiological variables entwined. It is allied to another complex phenomenon, that of genius.

From a neuroscience perspective, it is clear that various cerebral circuits are related to our ability not only to create, but also to use our creations imaginatively and, in certain fields such as the arts, to develop things not imagined before. These have an impact on those who hear or see (or touch or smell) the outputs of such creativity. From a clinical neuroscience perspective, one way to unravel the mysteries of human creativity is to 
study those with neurological and psychiatric disorders in which the creative energy and imagination is either enhanced or denied.

\section{References}

1. Koestler A. The Act of Creation. London: Arkana Penguin books; 1964.

2. Storr A. The Dynamics of Creation. London: Seker and Warburg; 1972.

3. Plucker J, Beghetto RA, Dow G. Why isn't creativity more important to educational psychologists? Potential, pitfalls, and future directions in creativity research. Educational Psychologist 2004; 39: 83-96

4. Lombroso C. The man of Genius. London: Walter Scott; 1891.

5. Nisbet JF. The insanity of Genius. London: Ward and Downey; 1893

6. Sully J. Genius and Insanity. Nineteenth Century 1885; 149: 948-969

7. Brain R. Some reflections on Genius and other Essays. London: Pitmans, 1960

8. Torriero S, Oliveri M, Koch G, Caltagirone C, Petrosini L. The what and how of observational learning. J Cogn Neurosci. 2007;19(10):1656-63.

9. Suddendorf T. The Rise of Metamind. In: Corballis MC, Lea EG Eds. The Descent of Man. Oxford: Oxford University Press,; 1999, p 218-259.

10. Kandel E. The Age of Insight. New York: Random House; 2012.

11. Heilman KM, Nadeau SE, Beversdorf DO. Creative Innovation: Possible Brain Mechanisms. Neurocase 2003; 9(5): 369-379

12. Flaherty AW. Frontotemporal and dopaminergic control of idea generation and creative drive. J Comp Neurol. 2005;493(1):147-53.

13. Costa VD, Tran VL, Turchi J, Averbeck BB. Dopamine modulates novelty seeking behavior during decision making. Behav Neurosci. 2014 Oct;128(5):556-66

14. Leggio MG, Molinari M, Neri P, Graziano A, Mandolesi L, Petrosini L. Representation of actions in rats: the role of cerebellum in learning spatial performances by observation. Proc Natl Acad Sci U S A. 2000;97(5):2320-5.

15. Caggiano V, Fogassi L, Rizzolatti G, Casile A, Giese MA, Thier P. Mirror neurons encode the subjective value of an observed action. Proc Natl Acad Sci U S A. 2012;109(29):11848-53.

16. Cotterill RM. Cooperation of the basal ganglia, cerebellum, sensory cerebrum and hippocampus: possible implications for cognition, consciousness, intelligence and creativity. Prog Neurobiol. 2001 May;64(1):1-33.

17. Lotze M, Erhard K, Neumann N, Eickhoff SB, Langner R. Neural correlates of verbal creativity: differences in resting-state functional connectivity associated with expertise in creative writing. Front Hum Neurosci. 2014;8:516 
18. Bogen JE, Bogen GM. Creativity and the corpus callosum. Psychiatrics of Clinical North America 1988; 11: 293-301.

19. Chávez-Eakle RA, Graff-Guerrero A, García-Reyna JC, Vaugier V, Cruz-Fuentes C. Cerebral blood flow associated with creative performance: a comparative study. Neuroimage. 2007 Nov 15;38(3):519-28

20. Jung-Beeman M, Bowden EM, Haberman J, Frymiare JL, Arambel-Liu S, Greenblatt R, Reber PJ, Kounios J. Neural activity when people solve verbal problems with insight. PLoS Biol. 2004;2(4):E97.

21. Beijamini F, Pereira SI, Cini FA, Louzada FM. After being challenged by a video game problem, sleep increases the chance to solve it. PLoS One. 2014;9(1):e84342.

22. Cai DJ, Mednick SA, Harrison EM, Kanady JC, Mednick SC. REM, not incubation, improves creativity by priming associative networks. Proc Natl Acad Sci U S A. 2009;106(25):10130-4

23. Palmiero M1, Di Giacomo D, Passafiume D Creativity and dementia: a review. Cogn Process. 2012;13(3):193-209.

24. Miller BL, Cummings J, Mishkin F, Boone K, Prince F, Ponton M, Cotman C. Emergence of artistic talent in frontotemporal dementia. Neurology. 1998;51(4):97882.

25. Miller ZA, Miller BL. Artistic creativity and dementia. Prog Brain Res. 2013;204:99112.

26. Miller BL, Hou CE. Portraits of artists: emergence of visual creativity in dementia. Arch Neurol. 2004 Jun;61(6):842-4.

27. Wu TQ, Miller ZA, Adhimoolam B, Zackey DD, Khan BK, Ketelle R, Rankin KP, Miller BL. Verbal creativity in semantic variant primary progressive aphasia. Neurocase. 2015 Feb;21(1):73-8.

28. Roberts JK, Robertson MM, Trimble MR. The lateralising significance of hypergraphia in temporal lobe epilepsy. J Neurol Neurosurg Psychiatry. 1982; 45(2): 131-8.

29. Rankin KP, Liu AA, Howard S, Slama H, Hou CE, Shuster K, Miller BL. A casecontrolled study of altered visual art production in Alzheimer's and FTLD. Cogn Behav Neurol. 2007 Mar;20(1):48-61.

30. Andreasen NC. Creativity and mental illness: prevalence rates in writers and their first-degree relatives. Am J Psychiatry. 1987;144:1288-92.

31. Jamison KR. Mood disorders and patterns of creativity in British writers and artists. Psychiatry. 1989;52:125-34.

32. Post F. Creativity and psychopathology. A study of 291 world-famous men. Br J Psychiatry. 1994;165:22-34.

33. Ludwig AM. Creative achievement and psychopathology: comparison among professions. Am J Psychother. 1992;46:330-56.

34. Ludwig AM. Mental illness and creative activity in female writers. Am J Psychiatry. 1994;151:1650-6. 
35. Trimble MR. The Soul in the Brain: The Cerebral Basis of Language, Art, and Belief. Baltimore: Johns Hopkins University Press; 2007

36. Cassano GB, Mula M, Rucci P, Miniati M, Frank E, Kupfer DJ, Oppo A, Calugi S, Maggi L, Gibbons R, Fagiolini A. The structure of lifetime manic-hypomanic spectrum. J Affect Disord. 2009;112(1-3):59-70.

37. Beigel, A., Murphy, D.L., 1971. Assessing clinical characteristics of the manic state. Am. J. Psychiatry 128, 44-50.

38. Robertson, G.M., 1890. Does mania include two distinct varieties of insanity and should it be subdivided? J. Ment. Sci. 36, 338-347.

39. Malhi GS, Yatham LN. Mania matters! Acta Psychiatr. Scand. 2007;116 (Suppl 434): $1-2$.

40. Akiskal HS, Akiskal KK. In search of Aristotle: temperament, human nature, melancholia, creativity and eminence. J Affect Disord. 2007;100:1-6.

41. Akiskal HS, Placidi GF, Maremmani I, Signoretta S, Liguori A, Gervasi R, Mallya G, Puzantian VR. TEMPS-I: delineating the most discriminant traits of the cyclothymic, depressive, hyperthymic and irritable temperaments in a nonpatient population. J Affect Disord. 1998;51:7-19.

42. Srivastava S, Childers ME, Baek JH, Strong CM, Hill SJ, Warsett KS, Wang PW, Akiskal HS, Akiskal KK, Ketter TA. Toward interaction of affective and cognitive contributors to creativity in bipolar disorders: a controlled study. J Affect Disord. 2010;125(1-3):27-34.

43. Mula M, Trimble MR. Music and madness: neuropsychiatric aspects of music. Clin Med. 2009;9(1):83-6.

44. Ludwig AM. The price of greatness. New York: The Guilford Press; 1995 